\title{
INVESTIGANDO AS PRÁTICAS PEDAGÓGICAS DOS PROFESSORES EM SERVIÇO NO ENSINO SUPERIOR COM ATUAÇÃO NA MODALIDADE EAD - SEMIPRESENCIAL
}

\author{
CURITIBA/PR MAIO/2018
}

\author{
Mariane Regina Kraviski - UNINTER - mariane.k@uninter.com \\ Dinamara Pereira Machado - UNINTER - dinamara.m@uninter.com \\ João Mattar - UNINTER - joao.ma@uninter.com
}

Tipo: Investigação Científica (IC)

Natureza: Planejamento de Pesquisa

Categoria: Métodos e Tecnologias

Setor Educacional: EDUCAÇÃO SUPERIOR

\begin{abstract}
RESUMO
Considerando que professores que estão sendo formados no século XXI, inseridos nos sistemas de educação formal, requerem de seus profissionais habilidades, competências didáticas e metodológicas, para as quais não vivenciaram, ou ainda, que podem não ter sido expostos durante sua formação. Diante disso, objetivamos averiguar sobre o conhecimento destes professores a respeito das metodologias ativas e da metodologia de Ensino Híbrido, em suas atuações em sala de aula de cursos semipresenciais de uma dada instituição. É importante registrar que os cursos pertencem à modalidade de educação a distância, que incorporou dois encontros semanais e, que de forma empírica, foi intitulado de semipresencial, mas o mesmo não corresponde ao proposto na legislação proposta de $20 \%$ a distância, conforme preconizado na resolução no 1134/2016. Para tanto, procedemos à construção deste cenário de pesquisa com a investigação destes professores, através da aplicação de questionários, para a obtenção de dados, para que, posteriormente, os resultados nos justifiquem a criação de uma capacitação de formação continuada de professores de ensino superior em serviço para o ensino híbrido. Desse modo observamos através dos resultados aqui expostos, que muito temos que investir na capacitação destes professores, o que permite concluir que muitos estão indo à sala de aula sem o preparo adequado e exigido para suas atividades de docência.
\end{abstract}

Palavras-chave: ensino híbrido, semipresencial, formação continuada, metodologias ativas 


\section{INTRODUÇÃO}

Professores que estão sendo formados no século XXI, hoje, inseridos nos sistemas de educação formal requerem dos profissionais habilidades, competências didáticas e metodológicas para as quais eles não foram e não estão sendo preparados. Diante deste cenário, foi desenvolvido este trabalho que faz parte das investigações realizadas para dar origem ao projeto de um curso de capacitação, o qual discute e apresenta uma formação continuada para professores em serviço para o uso do Ensino Híbrido nas salas de aula de cursos de graduação.

Desta forma, o objetivo principal deste artigo se deu no início das análises para criação da capacitação, que foi apurar qual o conhecimento e experiência de professores de Ensino Superior em serviço que atuam na modalidade semipresencial, com a metodologia de ensino híbrido, incorporando a utilização de metodologias ativas. Para tanto, constitui-se como campo para a pesquisa, uma instituição de ensino superior privada, que oferta cursos nas modalidades da Educação a Distância, Semipresencial e Presencial, localizada na região sul do país.

Para um diagnóstico introdutivo como base para as observações preliminares, foram coletadas informações substanciais de quarenta e quatro professores do Ensino Superior atuantes em cursos de licenciatura. Para que esta pesquisa se efetivasse, a primeira ação executada para prosseguimento ao desenvolvimento da investigação, foi a concepção de um questionário criado para mapear o conhecimento e a experiência dos professores com a metodologia semipresencial. Constatamos que os professores pesquisados não receberam capacitação específica e que foram para seu novo ambiente de trabalho, arraigados da cultura educacional apreendida ao longo dos anos da carreira profissional.

Para configuração deste trabalho, a estrutura foi concebida em três momentos, sendo eles: a. descrição do modelo dos cursos semipresenciais analisados; b. a metodologia de coleta de dados para fundamentar a pesquisa; c. análise e discussão dos dados obtidos na investigação.

\section{CURSO EAD - SEMIPRESENCIAL NA GRADUAÇÃO}

A modalidade a qual se pretende capacitar os professores para atuação, ofertada na instituição em questão, denominada aqui como Semipresencial, foi baseada na proposição "blended" de organização curricular. Entende-se blended, blended-learning ou b-learning, como um misto de atividades presenciais mescladas com momentos 
semipresenciais ou não presenciais (MUNHOZ, 2014) ou, como definido por Bacich, Tanzi Neto e Trevisani (2016), como uma

\footnotetext{
convergência de dois modelos de aprendizagem: o modelo presencial, em que o processo ocorre em sala de aula [...] e o modelo on-line, que utiliza as tecnologias digitais para promover o ensino. Podemos considerar que esses dois ambientes de aprendizagem, a sala de aula tradicional e o espaço virtual, tornam-se gradativamente complementares. [...] O papel desempenhado pelo professor e pelos alunos sofre alterações em relação à proposta de ensino considerado tradicional, e as configurações das aulas favorecem momentos de interação, colaboração e envolvimento com as tecnologias digitais Bacich et al. (2016, p. 52).
}

O curso semipresencial se estrutura a partir de uma sequência didática organizada de forma a contemplar diferentes estratégias e estilos de aprender, na qual o aluno tem a possibilidade de organizar seu estudo de maneira adequada às suas necessidades. $O$ conteúdo das disciplinas é ofertado através do Ambiente Virtual de Aprendizagem e, também, do material didático, o aluno realiza o autoestudo, respeitando seu ritmo pessoal e sendo autônomo. Duas vezes na semana, ocorrem momentos de interação presencial que são mediados pelos professores das respectivas disciplinas daquela fase de estudo. Nesses momentos presencias, a proposta didática é a Sala de Aula Invertida, ou Flepped Classroom, que tem como conceito e definição por Bergmann e Sams (2017, p. 11) que "o que tradicionalmente é feito em sala de aula, agora é executado em casa, e o que tradicionalmente é feito como trabalho de casa, agora é realizado em sala de aula"

O aluno estuda o conteúdo em casa e na sala de aula acontecem encontros dialógicos com implementação de diferentes metodologias ativas, com utilização de tecnologia digital ou não, cabendo ao critério de planejamento de cada professor.

\section{ELABORAÇÃO DO QUESTIONÁRIO - MÉTODO}

Para obtenção dos resultados acima aferidos, a investigação para início do desenvolvimento do curso de capacitação contou com uma primeira averiguação do objeto de estudo, que tem como foco a atuação de professores de licenciatura em cursos semipresenciais.

Foi necessário compreender o nível de conhecimento destes professores com relação à metodologia semipresencial, neste caso, o ensino híbrido, modalidade, esta, em que atuam, mas necessariamente não estavam adotando a prática do hibridismo que se é esperada para estes cursos. Quando verificamos suas aulas in $10 c 0$, ou quando indagamos os graduandos das licenciaturas, percebemos que muitas vezes eles continuam com os preceitos da escola em que o aluno era passivo e o professor ativo. 
Logo, o pontapé inicial foi desenvolver um questionário autoaplicável com o propósito de questiona-los a respeito de seu conhecimento e atuação nos cursos semipresenciais da instituição de ensino em que atuam.

Questionários autoaplicáveis são os questionários entregues aos respondentes para que eles mesmos os preencham. Podem ser enviados por correio, por e-mail ou internet (Vieira, 2009, p. 18). Neste caso, optamos por questionário enviado por internet, pois "são facilmente distribuídos, a coleta e o processamento dos dados são rápidos", ainda conforme Vieira.

O questionário foi elaborado com um total de dezessete perguntas, sendo dezesseis fechadas e uma aberta. As perguntas fechadas, pedem resposta quantitativa, mas o respondente deve se enquadrar em uma das alternativas que lhe são oferecidas. A pergunta aberta pede resposta qualitativa, quando o respondente escreve a resposta com suas próprias palavras (Vieira, 2009, p. 32).

O projeto de pesquisa e, por consequência o questionário, foi aprovado pelo Comitê de Ética da Instituição e está na Plataforma Brasi

\section{RESULTADOS E DISCUSSÕES}

$\mathrm{Na}$ análise dos resultados neste momento foram eliminadas as perguntas que tratam de informações de análise do perfil do respondente e consideramos as perguntas que tratam do ensino e aprendizagem e experiência do docente, que se tornaram relevantes para o objetivo da pesquisa.

No gráfico 1 é possível verificar que a maioria dos professores tem experiência com Ensino Presencial - EP e no Ensino a Distância - EAD, mas um menor número com experiência no Ensino Semipresencial - ESP.

Gráfico 1 - Quais das modalidades de ensino você atuou ou atua? 


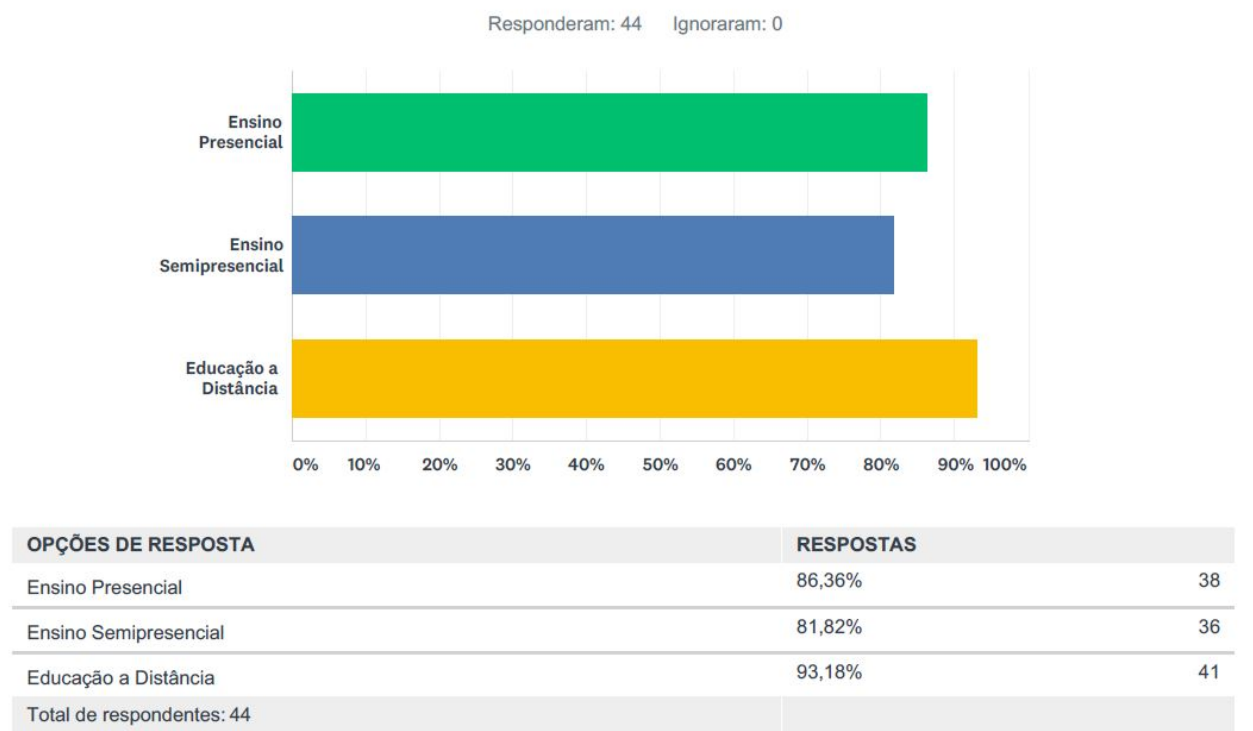

Fonte: a autora

Já, no Gráfico 2, é questionado a respeito da atuação do professor no ESP e verificamos que dez entre os quarenta e quatro respondentes nunca atuou. A resposta à esta pergunta, impossibilitou 0 avanço no questionário, pois o objetivo é verificar a experiência de professores atuantes ou que já atuaram nesta modalidade.

Gráfico 2 - Qual sua experiência de atuação na modalidade semipresencial?

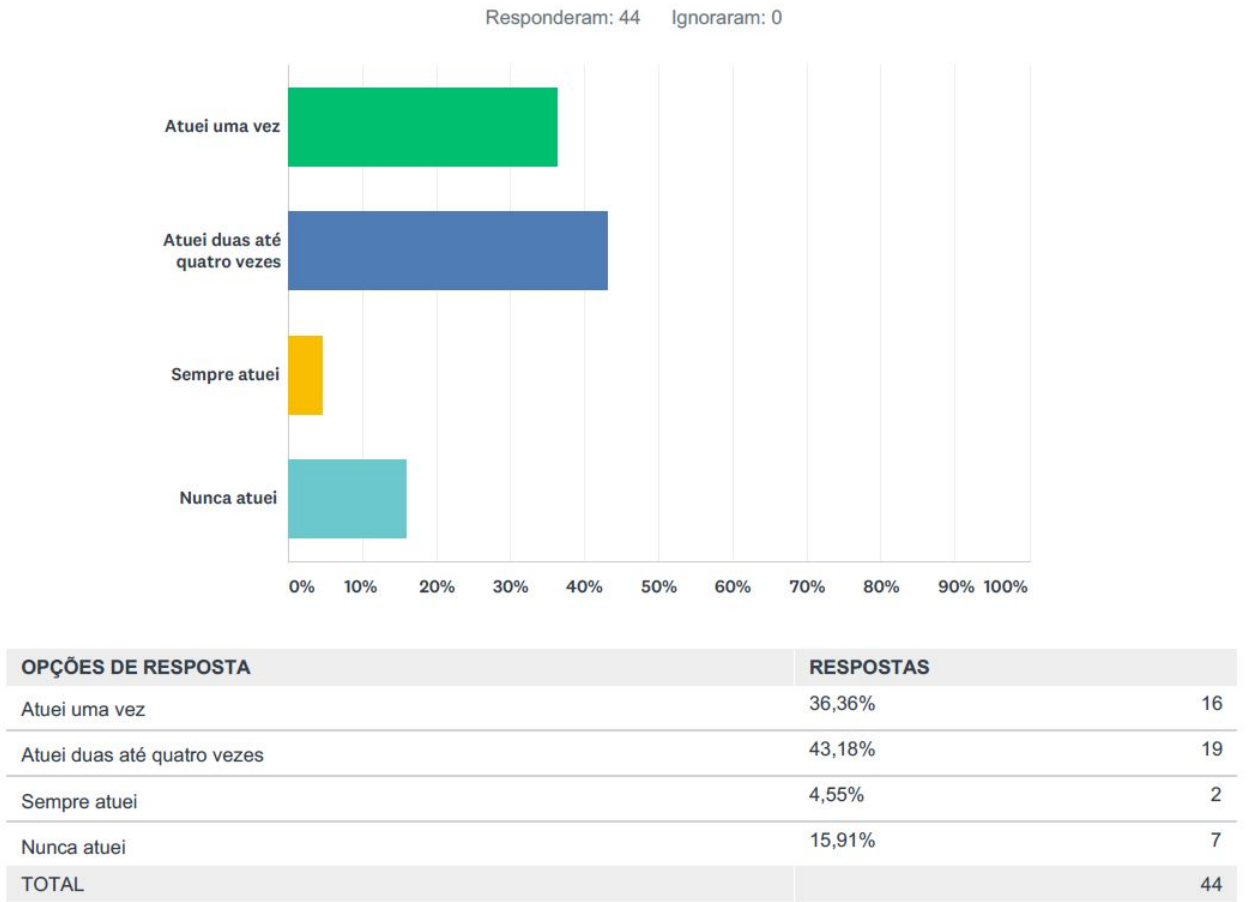

Fonte: a autora 
Quando instigado a respeito do conhecimento do Ensino Híbrido, uma grande maioria de professores diz não conhecer ou apenas ter ouvido falar sobre a metodologia, conforme verificado no Gráfico 3.

Gráfico 3 - Antes de atuar em cursos semipresenciais, conhecia a metodologia de Ensino Híbrido?

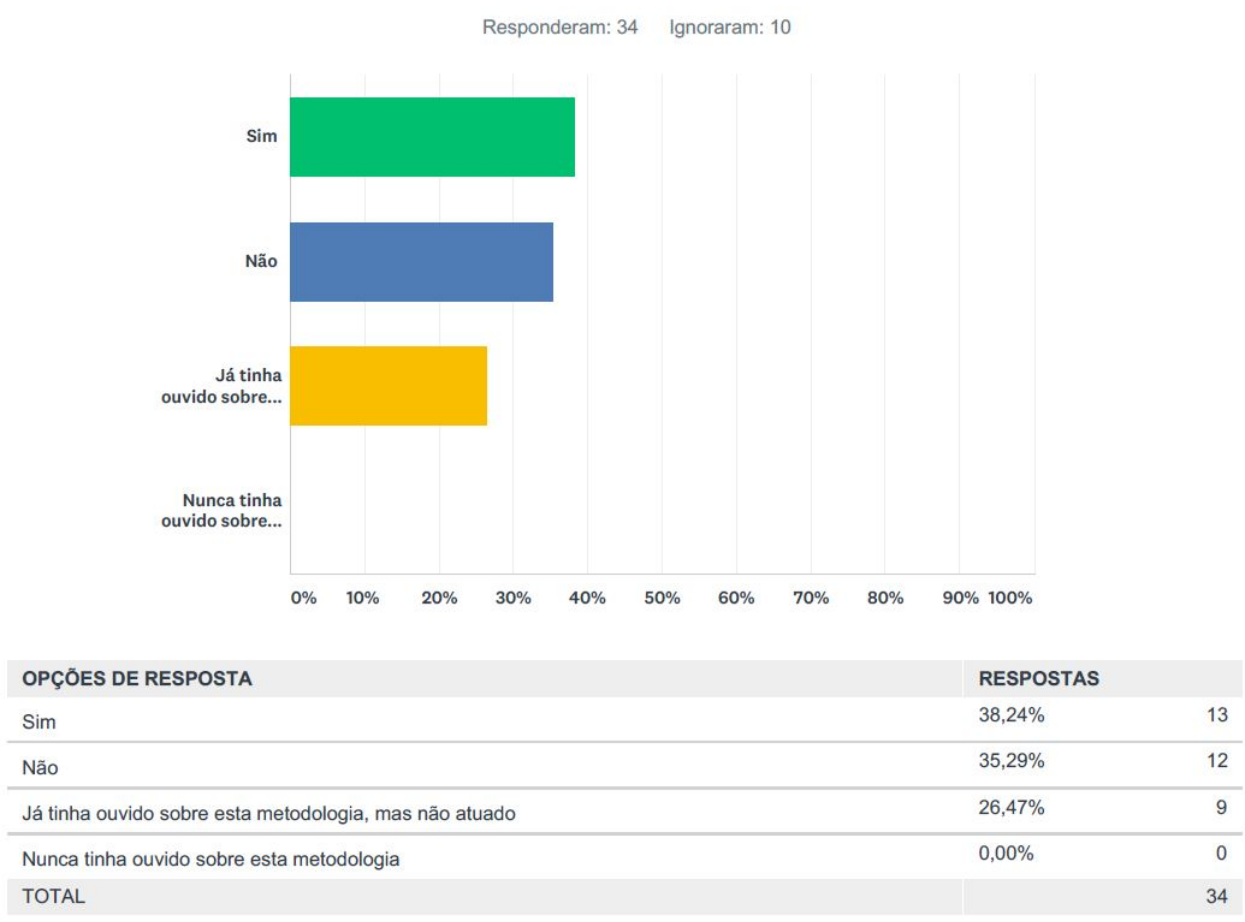

Fonte: a autora

Mas se contradizem, no Gráfico 4, quando responderam que utilizaram muitas vezes as metodologias ativas em sala de aula do semipresencial. Pensando que as metodologias ativas estão intimamente ligadas às práticas de uma sala de aula invertida, um dos modelos propostos no Ensino Híbrido, percebemos que estes professores se contradizem em suas respostas, talvez por certo modo intuitivo ou por não saberem sobre a totalidade de metodologias ativas disponíveis para esta modalidade.

Gráfico 4 - Qual é o seu conhecimento sobre as metodologias ativas para atuar na modalidade semipresencial? 


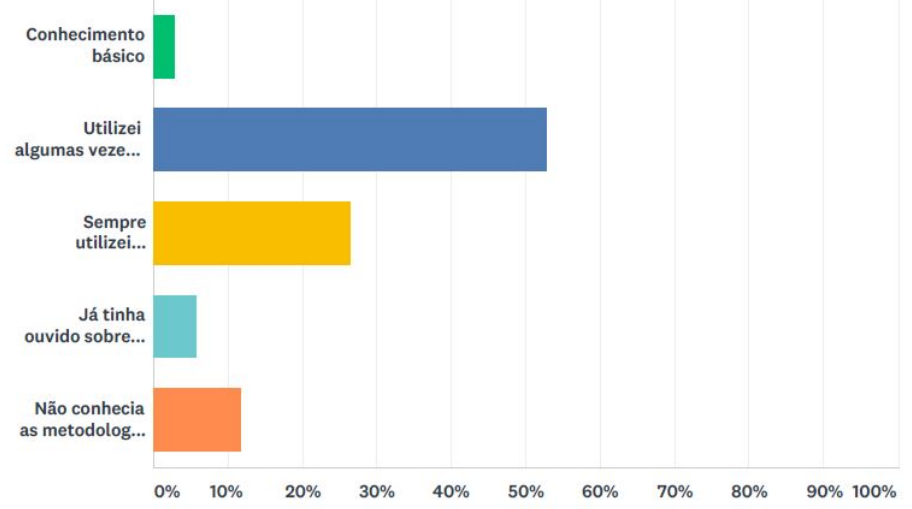

\begin{tabular}{llr}
\hline OPÇÕES DE RESPOSTA & RESPOSTAS \\
\hline Conhecimento básico & $2,94 \%$ & 1 \\
\hline Utilizei algumas vezes as metodologias ativas & $52,94 \%$ & 18 \\
\hline Sempre utilizei metodologias ativas em minhas aulas & $26,47 \%$ & 9 \\
\hline Já tinha ouvido sobre esta metodologia, mas nunca utilizado & $5,88 \%$ & 2 \\
\hline Não conhecia as metodologias ativas até atuar no semipresencial & $11,76 \%$ & 4 \\
\hline TOTAL & 34
\end{tabular}

Fonte: a autora

Constatamos que, no Gráfico 5, muitos dos professores foram para a sala de aula do semipresencial sem o conhecimento da metodologia adequada para esta modalidade, apenas com informações substanciais de que deveriam planejar em suas disciplinas.

Gráfico 5 - Para atuar na modalidade semipresencial você realizou capacitação?

Responderam: 34 Ignoraram: 10

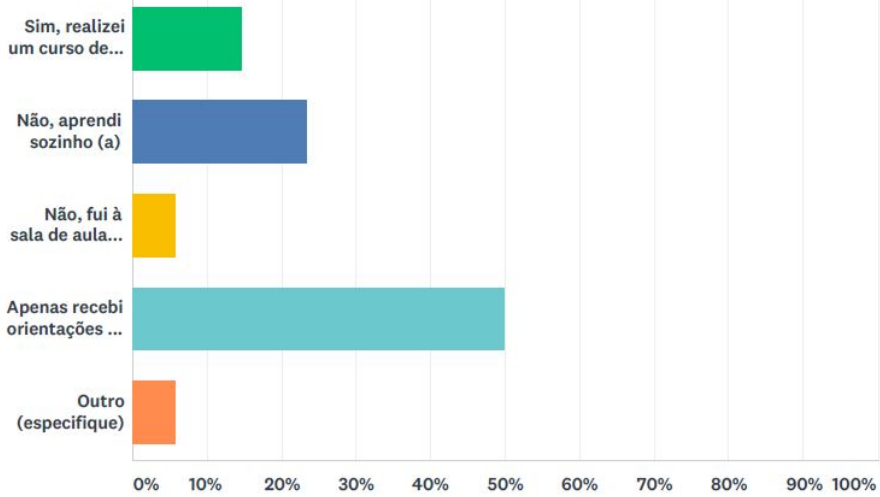

\begin{tabular}{llr}
\hline OPÇÕES DE RESPOSTA & RESPOSTAS \\
\hline Sim, realizei um curso de formação & $14,71 \%$ & 5 \\
\hline Não, aprendi sozinho (a) & $23,53 \%$ & 8 \\
\hline Não, fui à sala de aula sem experiência & $5,88 \%$ & 2 \\
\hline Apenas recebi orientações de como fazer & $50,00 \%$ & 17 \\
\hline Outro (especifique) & $5,88 \%$ & 2 \\
\hline TOTAL & & 34
\end{tabular}


Fonte: a autora

Percebemos, também, que não tiveram uma capacitação para o modelo de curso ou que aprenderam de maneira autônoma de como aplica-lo, mas que gostariam de uma capacitação, informação que se confirma no Gráfico 6, onde vinte e oito, dos trinta e quatro respondentes, afirmam que sim, acreditam ser essencial uma capacitação para sua atuação e, os outros seis respondentes, talvez, consideram importante, mas não necessário.

Gráfico 6 - Você considera importante realizar uma capacitação sobre a metodologia de Ensino Híbrido antes de atuar na modalidade semipresencial?

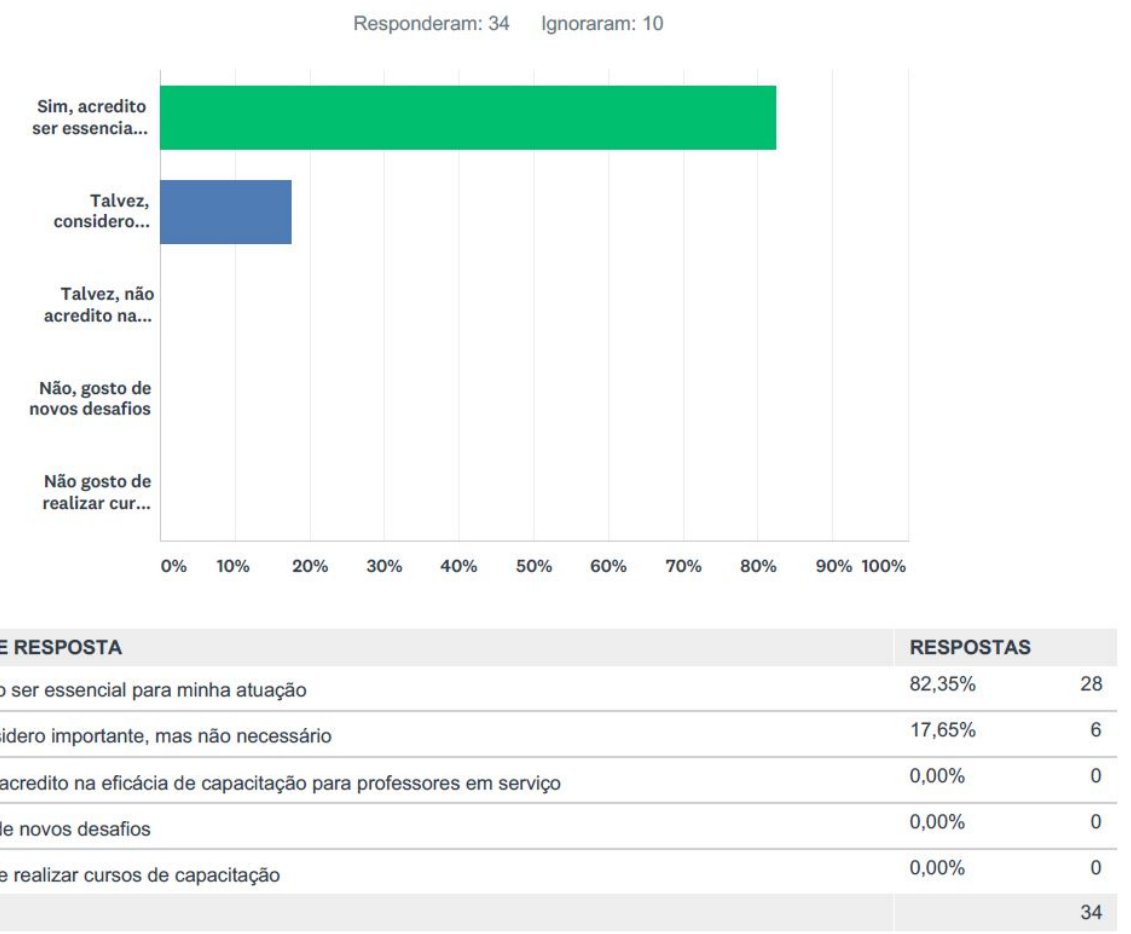

Fonte: a autora

\section{CONSIDERAÇÕES FINAIS}

Resultados apontam a necessidade de compreender que novas modalidades de ensino requerem novas práticas educacionais no contexto de cursos de licenciatura da modalidade de ensino semipresencial. Constatou-se que os professores pesquisados demandam de uma preparação focada na compreensão dos processos de aprendizagem por meio de novas concepções, na mudança de postura do educador, que se posicione como parceiro da construção do conhecimento de seus alunos, como 
mediador de todo o processo de ensino e aprendizagem, ainda que de toda a diversidade e da multiplicidade dos elementos envolvidos, seja do sujeito que aprende. Complementando a afirmação, podemos dizer que

Sabemos de forma empírica que ensinar constitui-se no plural, mas que aprender é um ato singular, que professores e alunos aprendem e ensinam, que os dois atores educacionais (professores e alunos) são ativos em suas atividades, assim deixamos registrado que as tendências educacionais suscitam no tempo e espaço (re) formulações de práticas colhidas e pesquisadas em outros momentos históricos (KRAVISKI, 2018).

O interesse pela utilização das metodologias ativas por parte dos professores é enorme, mas ainda não estão incorporadas efetivamente nas abordagens pedagógicas dos cursos semipresenciais, conclusão que podemos confirmar com dados obtidos no Censo EaD ABED 2016, comentado por MATTAR (p. 9, 2017),

Há, portanto, um reconhecimento (ao menos teórico) da importância que as metodologias ativas podem ter para a EaD, e isso já teria se refletido na incorporação de práticas mais ativas e ambientes virtuais de aprendizagem mais informais; mas a mudança ainda não pode ser observada da perspectiva da validação da aprendizagem.

A formação será legítima então quando contribuir para o desenvolvimento profissional do professor no âmbito de trabalho e de melhorias das aprendizagens profissionais (IMBERNÓN 2005). Instituições de Ensino Superior buscam constantemente investir na promulgação de metodologias inovadoras e a formação específica se torna primordial, tanto no início do processo quanto na continuidade da atividade (KRAVISKI, 2018).

\section{REFERÊNCIAS}

ABED - Associação Brasileira de Educação a Distância. Censo EAD.br: Relatório analítico da aprendizagem a distância no Brasil 2016. Curitiba: Intersaberes, 2017. 9 p.

BACICH, Lilian; NETO, Adolfo Tanzi; TREVISANI, Fernando De Mello. Ensino híbrido: Personalização e tecnologia na educação. Porto Alegre: Penso, 2016.

BERGMANN, Jonathan; SAMS, Aaron. Sala de aula invertida: uma metodologia ativa de aprendizagem. 1 ed. Rio de Janeiro: LTC, 2017. 11 p.

IMBERNÓN, Francisco. Formação docente e profissional: formar-se para a mudança é a incerteza. Coleção Questões da Nossa Época. 5a Edição. São Paulo: Cortez, 2005. 45 p. 
KRAVISKI, Mariane Regina. FORMAR-SE PARA FORMAR: APROPRIANDO-SE DO MODELO DE ENSINO HÍBRIDO PARA FORMAÇÃO CONTINUADA DE PROFESSORES EM SERVIÇO. In: Anais do III Simpósio Internacional sobre Desenvolvimento Profissional Docente e III Congresso Internacional sobre Formação e Desenvolvimento Profissional Docente. Anais...Curitiba(PR) UTFPR, 2018. Disponível em: <https//www.even3.com.br/anais/sidpd/78103-FORMAR-SE-PARA -FORMAR--APROPRIANDO-SE-DO-MODELO-DE-ENSINO-HIBRIDO-PARA-

FORMACAO-CONTINUADA-DE-PROFESSORES-EM-SERVI>. Acesso em: 16/05/2018 14:01

MUNHOZ, Antonio Siemsen. Tutoria em EAD: uma nova visão. 1 ed. Curitiba: Intersaberes, 2014. 29 p.

VIEIRA, Sonia. Como elaborar questionários. 1 ed. São Paulo: Atlas, 2009. 